\title{
Analisis Peran Komunikasi Visual Art Band Fourtwnty Sebagai Media Promosi
}

\author{
Greciana Herlin, Gregorius Genep Sukendro \\ Greciana.herlin123@gmail.com,Geneps@fikom.untar.ac.id \\ Fakultas Ilmu Komunikasi Universitas Tarumanagara
}

\begin{abstract}
Writing this paper aims to determine the Role of Communication Visual Art Band Fourtwnty as Media Promotion. The thing that makes the background of this paper is due to the visual art communication used to conduct a Fourtwnty band promotion. Researchers use qualitative research methods in completing writing this scientific paper, where with qualitative research methods researchers can find how to find problems that are the subject of discussion in the use of visual art communication as a promotional medium. The use of Surrealism and Pop Art, as a promotion used by the band Fourtwnty to get an attraction. The results of this study indicate that there is a successful use of visual art communication on promotions conducted by Ban Fourtwnty. Thus the results of this study can be used as useful reading for us all.
\end{abstract}

Keywords: band fourtwnty, promotion, Visual Art Communication.

\begin{abstract}
Abstrak
Penulisan karya tulis ini bertujuan untuk mengetahui Peran Komunikasi Visual Art Band Fourtwnty Sebagai Media Promosi. Adapun hal yang menjadikan latar belakang karya tulis ini dikarenakan komunikasi visual art yang digunakan untuk melakukan sebuah promosi band Fourtwnty. Peneliti menggunakan metode penelitian kualitatif dalam menyelesaikan penulisan karya tulis ilmiah ini, dimana dengan metode penelitian kualitatif peneliti dapat menemukan bagaimana cara untuk menemukan permasalahan yang dijadikan pokok pembahasan dalam penggunaan komunikasi visual art sebagai media promosi. Penggunaan aliran Surealisme dan Pop Art, sebagai promosi yang digunakan oleh band Fourtwnty untuk mendapatkan daya tarik. Hasil penelitian ini menunjukkan bahwa adanya keberhasilan penggunaan komunikasi visual art terhadap promosi yang dilakukan oleh band Fourtwnty. Dengan demikianlah hasil penelitian ini dapat dijadikan sebagai bacaan yang bermanfaat bagi kita semua.
\end{abstract}

Kata Kunci : band fourtwnty, Komunikasi Visual Art, Promosi.

\section{Pendahuluan}

Perkembangan media komunikasi yang secara terus berkembang berdampak mempengaruhi kehidupan masyarakat, dimana disisi lain media komunikasi sebagai kebutuhan manusia dalam memperoleh sebuah informasi. Dengan melalui media komunikasi visual kita mendapatkan informasi visual yang kita tangkap melalui penglihatan kita. Komunikasi Visual Art adalah salah satu subsektor industri bidang kreatif di Indonesia yang sangat berhubungan erat dengan konten visual pada periklanan. Komunikasi Visual Art merupakan penyesuaian nama Desain Grafis, penyesuaian nama ini karena adanya perkembangan media dan teknologi yang begitu 
pesat (menurut Moriarty, Mitchell dan Wells, dalam jurnal Rifqi Fadhlurrahman, 2018).

Media komunikasi visual memiliki 3 fungsi, yaitu sarana identifikasi, informasi, dan juga sebagai promosi. Salah satu tujuan dari komunikasi visual sebagai sarana promosi adalah untuk menyampaikan sebuah pesan, serta mendapatkan perhatian dari mata secara visual dan membuat pesan tersebut dapat diingat.

Menurut Zimmerer (dalam Freddy, 2009) promosi merupakan segala sesuatu bentuk macam komunikasi persuasi yang dirancang agar dapat menginformasikan kepada pelanggan tentang suatu produk atau jasa dan untuk mempengaruhi mereka agar tertarik untuk membeli suatu barang atau jasa yang mencakup publisitas, penjualan perorangan, serta periklanan.

Media informasi dan juga promosi merupakan suatu kebutuhan guna mempromosikan suatu barang atau jasa, dan dapat mempresentasikan citra suatu perusahaan serta memperkenalkan aktivitas yang dilakukan perusahaan tersebut secara detail yang dikemas semenarik mungkin untuk meningkatkan perkembangan perusahaan.

Menurut Tanoto dan Genep (dalam Jurnal Komunikasi, 2018) di era industri musik saat ini strategi promosi sangat amat dibutuhkan, terutama yang bergerak di bidang indie, situs jejaring sosial merupakan media yang sangat ampuh dalam memperkenalkan karyanya kepada orang banyak dan jangkauan yang tidak terbatas.

Dalam mempromosikan band mereka, mereka menggunakan komunikasi visual yang berunsur Surealisme dan unsur popart, Surrealisme, mengandung jiwa yang diangan-angankan dengan mengasingkan pemikiran fikiran. Popart sendiri adalah aliran seni yang memanfaatkan sebuah simbol - simbol dan gaya visual yang berasal dari media massa yang populer seperti yang terdapat di dalam televisi dan komik.

Menurut beberapa ahli, Band indie merupakan : 1. Sebuah tipe dari sebuah produksi musik yang bekerjasama dengan sebuah label rekaman independen (Small Independent Record Labels) dengan mendistribusikan secara independent. 2. Sebuah genre musik yang terdengar spesifik dan dengan cara serta gayanya tersendiri. 3 . Musik yang menampilkan spesifikasi karakteristik dan aspirasi jiwa dari sebuah karya musik. 4. Musik yang dapat menyatu dengan musik lain, seperti mainstream pop, dance, blues, country, atau classical (dalam jurnal Irbah, Haryani., Rachma, Yuliani., Salmiyah, Dini, 2015)

Salah satu band indie Indonesia yang menggunakan visual art dalam promosinya adalah band Fourtwnty. Band indie Fourtwnty bentukan dari Roby geisha ini sedang naik daun berkat lagunya yang berjudul "Zona Nyaman". Lagu tersebut merupakan OST dari film "Filosofi Kopi 2: Ben \& Jody" yang tayang pada 13 juli 2017. (dalam jadiberita.com yang ditulis oleh Hutomo Dwi)

Dalam penelitian ini, peneliti memilih band indie Fourtwnty sebagai subjek dari penelitian. Fourtwnty menggunakan komunikasi visual art sebagai upaya mereka mempromosikan band mereka agar dikenal oleh khalayak luas. Penelitian ini dimaksud untuk mengetahui bagaimana peran komunikasi visual art pada band Fourtwnty dalam melakukan promosi. Dengan adanya penelitian ini dapat diketahui bagaimana peran dari visual art terhadap promosi band Fourtwnty.

Berdasarkan latar belakang yang sudah dijelaskan sebelumnya maka dapat disimpulkan permasalahan sebagai berikut: Bagaimana memahami komunikasi visual art yang dipakai oleh band Fourtwnty sebagai media promosi? 


\section{Metode Penelitian}

Dalam penelitian ini peneliti menggunakan metode penelitian kualitatif untuk meneliti analisis peran komunikasi visual art band Fourtwnty sebagai media promosi. Menurut Sugiyono (2016), metode penelitian kualitatif merupakan metode penelitian yang digunakan untuk meneliti suatu obyek yang alamiah, dimana peneliti adalah suatu instrumen kunci, teknik pengumpulan data dilakukan secara triangulasi (gabungan), analisis data bersifat induktif dan hasilnya lebih menekankan kepada makna daripada generalisasi.

Untuk mengetahui peran komunikasi visual art pada band Fourtwnty sebagai promosi maka dilakukan penelitian kualitatif dengan memanfaatkan wawancara terbuka untuk memahami sikap, pandangan, perasaan seseorang, hingga perilaku individu atau sekelompok orang. Metode kualitatif digunakan untuk mendapatkan data yang mendalam, suatu data yang mengandung makna. Oleh karena itu dalam penelitian kualitatif tidak menekankan pada generalisasi, tetapi lebih menekankan pada makna. Pemilihan metode ini juga dibangun oleh pendekatan terhadap para pecinta seni dan band Fourtwnty.

Dengan ini peneliti menggunakan penelitian kualitatif dengan pendekatan secara fenomenologis. Dimana peneliti akan terjun langsung kelapangan dengan mengamati fenomena yang terjadi dilapangan secara alamiah. Penelitian ini akan dibedakan sesuai dengan masing-masing jenis penelitian dan fokus penelitian, apakah penelitian tersebut fokus pada budaya, fenomena, kasus dan sebagainya.

Fenomenologi menurut Gertz (1973) dalam (Nurdin dan Hartati 2019), menekankan kepada aspek subjektif dari tingkah laku manusia; disini peneliti masuk ke dalam dunia sebuah konseptual subjek agar peneliti mengerti apa makna yang mereka bentuk di sekitar peristiwa di dalam kehidupan sehari-hari mereka. Hal ini dapat dipahami, bahwa penelitian fenomenologi adalah suatu pandangan yang menekankan pada pengalaman-pengalaman serta bagaimana menginterpretasikan pengalamannya tersebut.

Objek penelitian yang ditetapkan oleh peneliti mengacu pada peran komunikasi visual art band Fourtwnty sebagai media promosi. Sedangkan subjek penelitian yang dipilih oleh peneliti adalah band Fourtwnty. Dilihat dari pengalaman manusia dapat dipahami bahwa setiap orang akan melihat realita yang berbeda pada situasi yang berbeda dengan waktu yang berbeda. Dalam penelitian ini peneliti akan menggunakan metode studi kasus, Menurut Kriyantono (2010), studi kasus merupakan metode yang menggunakan berbagai banyak sumber data yang bisa digunakan oleh peneliti untuk meneliti serta menjelaskan secara jelas di berbagai aspek individu suatu kelompok, maupun program.

Dalam buku Paul Martin Lester tahun 2014, menekankan enam perspektif untuk menganalisis sebuah gambar, beberapa metode kritikal untuk menganalisis gambar, salah satunya adalah Cultural Perspective, sebuah sejarah perspektif yang membawa kita untuk mencari tahu tentang arti simbol-simbol tersebut di suatu media.

\section{Hasil Temuan dan Diskusi}

Penulis menemukan kegiatan promosi yang dilakukan oleh band Fourtwnty dengan menggunakan komunikasi visual art. Dalam melakukan sebuah promosi, pembuat bisnis harus kreatif dalam membuat sebuah konten sebagai identitas perusahaan tersebut ataupun sebagai pembanding dengan akun bisnis lainnya. 
Cultural Perspective merupakan sejarah pada masa lampau yang membawa kita untuk mencari tahu suatu simbol atau makna pada gambar di suatu media (dalam buku Paul Martin Lester, 2014). Cultural Perspective berkaitan dengan adanya adaptasi budaya barat di dalam karya salah satu seniman Indonesia yaitu band Fourtwnty, pengaruh budaya yang masuk ikut juga mempengaruhi dalam melakukan promosi band Fourtwnty di Instagram dengan menggunakan komunikasi visual art.

Band Fourtwnty menggunakan teknik visual art sebagai desain dari cover promosi mereka, tidak banyak elemen visual yang dibuat di dalamnya untuk mengundang imajinasi publik untuk membuat cerita sendiri dari apa yang ingin diungkapkan band Fourtwnty, tidak banyak aspek yang berpotensi memberikan identitas visual tersendiri bagi band Fourtwnty yang membedakan dengan band indie lainnya. Dilihat dari respon publik promosi yang dilakukan oleh band Fourtwnty mendapatkan tanggapan yang baik.

Objek penelitian yang ditetapkan oleh peneliti mengacu pada peran komunikasi visual art band Fourtwnty sebagai media promosi. Sedangkan subjek penelitian yang dipilih oleh peneliti adalah band Fourtwnty. Band Fourtwnty menggunakan teknik visual art sebagai desain dari cover promosi mereka, tidak banyak elemen visual yang dibuat di dalamnya untuk mengundang imajinasi publik untuk membuat cerita sendiri dari apa yang ingin diungkapkan band Fourtwnty, tidak banyak aspek yang berpotensi memberikan identitas visual tersendiri bagi band Fourtwnty yang membedakan dengan band indie lainnya. Dilihat dari respon publik promosi yang dilakukan oleh band Fourtwnty mendapatkan tanggapan yang baik.

Band Fourtwnty sendiri pun tidak menerapkan konsep yang teoritis dalam strategi promosi mereka. Sebagai strategi promosi diharapkan komunikasi visual ini mampu membangun respon publik untuk pencapaian yang lebih luas lagi. Dengan kualitas konten visual pada postingan di Instagram dapat membantu terbentuknya identitas band atau brand image yang memiliki value. Hal menariknya adalah bagaimana band Fourtwnty mengangkat komunikasi visual dengan konsep desain Surealisme dan Pop Art sebagai gaya ilustrasi ke dalam sebuah promosi mereka di Instagram.

Menurut Laurence (dalam Edward Lucie, 1996) Surealisme merupakan suatu karya seni yang menggambarkan ketidak laziman atau sesuatu hal di luar logika, gerakan ini juga menggambarkan gagasan tentang sebuah mimpi, ilusi, dan fantasi. Sementara itu, Pop Art menurut Sipperley (dalam buku Adityawan Arief tahun 2013) merupakan lukisan Pop Art yang cenderung memiliki warna-warna yang sangat mencolok, biasanya terdiri dari warna merah, kuning, dan biru, bisa dilihat dalam cover-cover band Fourtwnty yang banyak terdapat warna-warna mencolok.

Pengertian dari Visual Art adalah budaya visual, semua bentuk visual yang muncul yang ada di masyarakat Indonesia maupun di luar.

Salah satu referensi yang diikuti style nya adalah yellow submarine dari the beatles, Dalam Film Yellow Submarine Beatles juga ingin menunjukkan bahwa band rock seperti The Beatles juga bisa menyenangkan untuk anak-anak, sehingga mereka membuat film tersebut dengan menggunakan visual yang mengandung unsur seni.

Jika band The Beatles menggunakan komunikasi visual art sebagai film untuk mempromosikan band mereka, tidak jauh berbeda dengan band Fourtwnty yang juga menggunakan komunikasi visual sebagai media promosi mereka. Band Fourtwnty ingin menunjukan rasa toleransi dari desain visual tersebut. 
Band Fourtwnty ingin membangun yaitu image Fourtwnty yang kaya akan pesan-pesan toleransi dan kesederhanaan. Band fourtwnty menggunakan visual yang menunjukkan sisi yang berbeda dari band indie lainnya, visual yang mengandung aliran surealisme mereka pakai sebagai media promosi mereka. Band Fourtwnty juga menggunakan visual tersebut dalam mempromosikan konser mereka yang bertajuk Heliotropisme.

cover yang dipakai oleh band Fourtwnty tidak jauh berbeda dengan cover the beatles yang mengandung unsur seni Psychedelic Art yang artinya seni yang proses penciptaannya terinspirasi oleh pengalaman-pengalaman atau bentuk kesadaran akibat obat-obatan yang menyebabkan semacam halusinasi. Dilihat dari ilustrasi yang mereka buat bahwa ilustrasi tersebut ditunjukkan untuk fans mereka yang berusia sekitar umur 20-an atau bisa dibilang dengan generasi milenial.

Generasi milenial (dalam Sri dan Nur, 2018) adalah kelompok demografi setelah Gen-X Tidak ada batasan waktu yang pasti untuk awal dan akhir dari kelompok. Para ahli dan juga peneliti biasanya menggunakan awal 1980-an sebagai awal dari kelahiran kelompok ini dan juga pertengahan tahun 1990an hingga awal tahun 2000-an sebagai akhir dari kelahiran. Gen milenial pada umumnya merupakan anak-anak dari generasi Baby Boomers dan Gen X yang tua. Milenial kadang disebut sebagai "Echo Boomers" karena adanya "booming" atau peningkatan besar, tingkat kelahiran pada tahun 1980-an dan 1990-an.

Jika dilihat dari segi fans promosi yang band Fourtwnty lakukan tidak hanya tertuju kepada anak-anak milenial saja, tetapi dilihat dari segi tema dalam promosi mereka terdapat komunikasi visual yang unik sehingga orang yang mengerti art pun bisa ikut mengartikan gambar-gambar yang band Fourtwnty perlihatkan. Jika dilihat dari segi generasi ilustrasi yang band Fourtwnty pakai menggunakan visual-visual tahun 60-an, yang di mana band Fourtwnty mengajak generasi tahun 60-an untuk bernostalgia dengan adanya visual tersebut.

\section{Kesimpulan}

Berdasarkan hasil penelitian dan hasil dari pembahasan ini, maka dapat ditarik kesimpulan dari penelitian ini sebagai berikut.

Berpromosi dengan menggunakan komunikasi visual dianggap media yang tepat yang dapat membantu band Fourtwnty dengan mudah dikenal oleh masyarakat yang lebih luas lagi, karena keunikan mereka yang menggunakan komunikasi visual dalam promosi cover mereka. kelebihan dari strategi promosi yang band Fourtwnty lakukan adalah memberikan warna yang berbeda dengan memberikan filosofi dan cerita pendek mengenai makna dari ilustrasi yang terdapat di cover mereka.

\section{Ucapan Terima kasih}

Penelitian ini dapat terlaksana karena bantuan dan dukungan dari banyak pihak. Oleh sebab itu, peneliti ingin menyampaikan rasa terima kasih yang sebesarbesarnya kepada keluarga.

\section{Daftar Pustaka}

Adityawan S, Arief \& Tim Litbang Concept. (2010). Tinjauan Desain Grafis dari Revolusi Industri Hingga Indonesia Kini. Jakarta: PT Concept Media. 
Dwi, Hutomo. (2017, November 18), Kenalan dengan Fourtwnty, Band Indie Bentukan Roby Geisha yang Naik Daun Berkat Filosofi Kopi 2. Desember 12, 2019. Jadiberita.com. http://jadiberita.com/120907/kenalan-denganfourtwnty-band-indie-bentukan-roby-geisha-yang-naik-daun-berkat-filosofikopi-2.html.

Fadlurrahman, Rifqie. (2018). Pembuatan Konten Visual Kreatif Harian Untuk Media Sosial Produk Pt. Sinar Sosro Menggunakan Adobe Creative Cloud 2017. Jurnal Studi Teknik Multimedia Dan Jaringan Politeknik, 1-7.

Irbah, Haryani., Rachma P, Yuliani., Salmiyah F, Dini. (2015). Strategi Komunikasi Penggunaan Media Sosial Sebagai Media Promosi Band Indie Mustache And Beard. Jurnal Komunikasi, 2.

Kriyantono, Rakhmat. (2010). Teknik Riset Komunikasi. Kencana: Jakarta

Lucie S, Edward. (1996). Visual Art In The Twentieth Century. London: Laurence King Publishing.

Martin L, Paul. (2014). Visual Communication: Images With Messages, Sixth Edition. Boston USA: Premediaglobal.

Nurdin, Ismail., \& Hartati, Sri. 2019. Metodologi Penelitian Social. Surabaya: Media Sahabat Cendekia.

Rangkuti, Freddy. (2019), Strategi Promosi yang Kreatif dan Analisis Kasus Integrated Marketing Communication. Jakarta: PT Gramedia Pustaka Utama.

Soelistyowati, Sri., \& Nur S, Pri Budiarta. (2018). Profil Generasi Milenial Indonesia. Jakarta: Kementerian Pemberdayaan Perempuan dan Perlindungan Anak.

Sugiyono. (2016). Memahami Penelitian Kualitatif. Bandung: Alfabeta.

Tanoto, Bagas, \& Genep S, Gregorius. (2018), Strategi Komunikasi Pemasaran Band Indie Fourtwnty Dalam Industri Musik Indonesia. Jurnal Komunikasi, 2(1). 